\title{
Oncologic Outcomes of Organ Preserving Approaches in Patients With Rectal Cancer Treated With Preoperative Chemoradiotherapy
}

\author{
In Ja Park, Jong Lyul Lee, Yong Sik Yoon, Chan Wook Kim, Seok-Byung Lim, Chang Sik Yu, Jin Cheon Kim \\ Department of Colon and Rectal Surgery, Asan Medical Center, University of Ulsan College of Medicine, Seoul, Korea
}

Purpose: We evaluated the oncologic outcomes of organ-preserving strategies in patients with rectal cancer treated with preoperative chemoradiotherapy (PCRT).

Methods: Between January 2008 and January 2013, 74 patients who underwent wait-and-watch $(\mathrm{WW})(\mathrm{n}=42)$ and local excision (LE) $(\mathrm{n}=32)$ were enrolled. Organ-preserving strategies were determined based on a combination of magnetic resonance imaging, sigmoidoscopy, and physical examination 4-6 weeks after completion of PCRT. The rectum sparing rate, 5-year recurrence-free survival (RFS), and overall survival (OS) were evaluated.

Results: The rectum was more frequently spared in the LE $(100 \%$ vs. $87.5 \%, \mathrm{P}=0.018)$ at last follow-up. Recurrence occurred in $9(28.1 \%) \mathrm{WW}$ and $7(16.7 \%) \mathrm{LE}(\mathrm{P}=0.169)$. In the WW, 7 patients had only luminal regrowth and 2 had combined lung metastasis. In the LE, 2 (4.8\%) had local recurrence only, 4 patients had distant metastasis, and 1 patient had local and distant metastasis. Among 13 patients who indicated salvage surgery (WW, $\mathrm{n}=7 ; \mathrm{LE}, \mathrm{n}=11$ ), all in the WW received but all of LE refused salvage surgery $(\mathrm{P}=0.048)$. The 5 -year OS and 5 -year RFS in overall patients was $92.7 \%$ and $76.9 \%$, respectively, and were not different between WW and LE $(\mathrm{P}=0.725, \mathrm{P}=0.129)$.

Conclusion: WW and LE were comparable in terms of 5-year OS and RFS. In the LE group, salvage treatment was performed much less among indicated patients. Therefore, methods to improve the oncologic outcomes of patients indicated for salvage treatment should be considered before local excision.

\section{Keywords: Rectal neoplasms; Organ preservation; Watch-and-wait; Treatment outcome}

\section{INTRODUCTION}

The surgical principle of total mesorectal excision has resulted in improved oncologic outcomes. It decreases the local recurrence rate in locally advanced rectal cancer combined with preoperative chemoradiotherapy (PCRT). However, total mesorectal excision is associated with perioperative morbidity and impaired quality of

Received: January 20, 2019 - Accepted: March 17, 2019

Correspondence to: In Ja Park, M.D.

Department of Colon and Rectal Surgery, Asan Medical Center, University of Ulsan College of Medicine, 88 Olympic-ro 43-gil, Songpa-gu, Seoul 05505, Korea

Tel: +82-2-3010-3937, Fax: +82-2-474-9027, E-mail: ipark@amc.seoul.kr ORCID code: https://orcid.org/0000-0001-5355-3969

(C) 2019 The Korean Society of Coloproctology

This is an open-access article distributed under the terms of the Creative Commons Attribution NonCommercial License (http://creativecommons.org/licenses/by-nc/4.0) which permits unrestricted noncommercial use, distribution, and reproduction in any medium, provided the original work is properly cited. life [1-4]. Many patients experience bladder/sexual dysfunction or low anterior resection syndrome, and some require a permanent stoma [2-4]. Therefore, clinicians have tried to identify treatment strategies that maintain quality of life without compromising oncologic outcomes.

PCRT results in various degrees of responses, and $15 \%-30 \%$ of patients showed complete regression of primary tumor $[5,6]$. Organ-preserving approaches have gained popularity after several studies showed that good response to PCRT was a predictor for good oncologic outcomes [6, 7]. Organ-preserving approaches such as local excision (LE) or wait-and-watch (WW) for patients with clinical complete (cCR) or near complete regression after PCRT provide the undeniable benefits of avoiding surgical complications and the emotional and practical difficulties of living with a stoma. Organ preserving approaches in rectal cancer surgery must not impair oncologic outcomes. Many studies reported comparable oncologic outcomes after LE in the early period of 
organ-preserving approaches [8-10]. The most attractive factor of $\mathrm{LE}$ is pathologic confirmation of primary tumor regression. In cases of pathologically confirmed complete regression of primary tumor, the overall survival (OS) rate after LE was comparable with that after radical resection [8-10].

LE does not provide information about lymph node metastasis, an important prognostic factor. In addition, some studies reported that a long interval between completion of PCRT and surgical intervention improved tumor response $[11,12]$. Therefore, WW has recently gained support. However, insufficient accuracy in assessing tumor regression level after PCRT is a limitation regarding the decision to undergo $\mathrm{WW}$ and surveillance.

Although many studies regarding organ preserving approaches after PCRT have been reported recently, these studies included a small number of patients and only one type of organ preserving approach. There was no clear evidence for the benefit of confirming pathologic tumor regression grade (TRG) using LE or differences in clinical/oncological outcomes between LE and WW. Therefore, clinical confusion remains when determining which type of organ preserving approach to perform.

In this study, we assessed the oncologic outcomes of LE and WW approaches for patients with rectal cancer who showed good clinical response after PCRT and evaluated the clinical course of patients who underwent each approach.

\section{METHODS}

\section{Patients and treatment}

This study included patients who underwent WW and LE for rectal cancer after PCRT between January 2008 and December 2012 at Asan Medical Center. During the study period, 2,832 patients underwent PCRT for rectal cancer and 2,758 patients received radical resection. A total of 74 patients who received organ preserving strategies such as WW and LE were included. Among them, 42 patients received LE and 32 patients received WW. Those with unavailable pathology results, synchronous metastatic disease, and who could not complete PCRT were excluded from analysis. This study was approved by the Institutional Review Board (IRB) of Asan Medical Center (approval number: 20171022) and informed consent was waived according to IRB regulations.

Patients received a total dose of 50-50.4 Gy radiotherapy with 22 to 25 fractions of local irradiation in the pelvis, $1.8-2.0 \mathrm{~Gy}$ each, 5 times a week for 5 weeks and a boost dose of 5.4-6.0 Gy radiation to the primary tumor over 3 days. Concurrent chemotherapy consisted of either oral administration of capecitabine $\left(825 \mathrm{mg} / \mathrm{m}^{2}\right)$ twice daily or 2 cycles of intravenous bolus injection of 5-fluorouracil (5-FU, $375 \mathrm{mg} / \mathrm{m}^{2} /$ day) and leucovorin $(20 \mathrm{mg} /$ $\mathrm{m}^{2} /$ day) for 3 days during the 1 st and 5 th week of radiotherapy. Some patients also received oxaliplatin as a combined regimen.

All patients were re-examined by physical examination, rectal magnetic resonance imaging (MRI), abdominopelvic computed tomography (CT), chest CT, and sigmoidoscopy at 4-6 weeks after PCRT completion. Organ-preserving strategies were determined based on a combination of the re-evaluation results. Organ-preserving strategies were suggested to patients with clinically complete or near complete regression of primary tumor and no evidence of radiologic lymph node metastasis or distant metastasis. Determination of LE or WW approach was decided following discussion between the surgeon and patient and consideration of medical condition, age, and socioeconomic circumstances. LE was performed 6-10 weeks after completion of PCRT. Pathologic examination was performed by pathologists specialized in colorectal cancer pathology. Pathologic responses to PCRT were evaluated in resected specimens using the TRG system according to the proportion of tumor cells and fibrosis suggested by the Gastrointestinal Pathology Study Group of the Korean Society of Pathologists [13]. Patients pathologically diagnosed with $\geq \mathrm{ypT} 2$ disease were strongly recommended to undergo immediate salvage radical resection after LE. Indeed, salvage operation was also recommended for patients with deep submucosa (SM) invasion ( $\geq$ ypSM2), lymphovascular invasion, perineural invasion, tumor budding, and margin involvement.

\section{Surveillance and oncologic outcome}

Digital rectal examination, laboratory studies including carcinoembryonic antigen (CEA) level, and sigmoidoscopy were performed every 3 months during the first 2 years after operation. An abdominopelvic CT scan and chest CT scan were performed every 6 months for patients who underwent LE. Colonoscopy was performed every 2-3 years. For patients managed by WW, digital rectal examination, sigmoidoscopy, CEA measurement (every 3 months in the first 2 years and then every 6 months), CT scan of the chest, abdomen, and pelvis (every 6 months for 5 years), and colonoscopy (every 2-3 years) were performed after first postPCRT assessment.

Local regrowth was defined as clinical, endoscopic, or radiologic evidence of intraluminal tumor. Luminal regrowth identified within 12 months was categorized as early regrowth. Local recurrence was defined as presence of tumor within the rectal wall after excision or within the mesorectum.

Recurrence-free survival (RFS) and OS were counted from the day of LE or completion of PCRT to the date of the first recurrence event. For patients indicated for salvage resection, the 5-year RFS after salvage resection (sRFS) was analyzed.

\section{Statistical analysis}

Clinicopathologic characteristics were analyzed using chi-square tests, independent-sample t-tests, and logistic regression. Oncologic outcomes such as RFS, sRFS, and OS were evaluated using the Kaplan-Meier method with the log rank test. Statistical significance was defined as $\mathrm{P}<0.05$, and all analyses were performed using IBM SPSS Statistics ver. 21.0 (IBM Co., Armonk, NY, USA). 


\section{RESULTS}

\section{Clinical characteristics}

The study included 32 patients in the WW group and 42 in the LE group. The median dose of radiotherapy was $50.4 \mathrm{~Gy}$. The most commonly used chemotherapeutic regimen in PCRT was 5-fluorouracil and leucovorin (47.9\%). Median serum CEA before PCRT was $2.2 \mathrm{ng} / \mathrm{mL}$ (interquartile range [IQR], 1-7.2 ng/mL). Age, sex, and follow-up duration did not differ between LE and WW groups. Median pre-PCRT CEA was higher in the $\mathrm{WW}$ group $(\mathrm{P}=$ 0.001). Pre-PCRT cT3-4 was more common in the $\mathrm{WW}(\mathrm{P}=$ 0.002 ) group and pre-PCRT $\mathrm{cN}+$ was also significantly more common in the WW $(\mathrm{P}<0.001)$ group. Median follow-up duration was 68 months (IQR, 57-88 months) in all patients (Table 1).

\section{Pathologic and clinical outcomes after LE and salvage treatment}

In the LE group, 22 patients were confirmed to have total primary tumor regression. Five patients had $\geq y p T 2$ disease ( 4 ypT2 and 1 ypT3). Five patients had tumor confined within the mucosa, and 9 patients had tumor invading the SM. Nine patients had near total regression and 8 patients had moderate regression. Eleven patients who were recommended for salvage resection refused to undergo salvage resection. Among them, 5 patients experienced recurrence. Three patients had distant metastasis, 1 had only local recurrence, and 1 experienced combined local and systemic recurrence. One patient with ypT3 disease and 1 patient with ypT2 disease were free of recurrence for 73 and 43 months, respectively. In the WW group, 9 patients experienced luminal regrowth and 1 patient had synchronous distant metastasis. Five patients had early luminal regrowth. Eight patients with luminal regrowth were referred to salvage resection, and all of them received salvage resection. Of these resections, 2 were LEs, 2 were abdominoperineal resections, and 3 were sphincter preserving radical resections. Among 8 patients who received salvage resection, 5 experienced postoperative recurrence. All except 1 patent, who had distant lymph node metastasis detected at 14 postopertive months, occurred within 1 year; 3 had lung metastasis and 1 had mesorectal lymph node metastasis (Fig. 1).

\section{Clinical and oncologic outcomes}

Postoperative complications occurred in $23 \%$ of the LE group and $33.3 \%$ of the WW group after salvage resection. In the LE group, the most common complication was anal pain, which occurred in 6 patients (14.3\%). Incontinence developed in 2 patients, voiding difficulty developed in 1 patient, and perirectal inflammation re-

Table 1. Clinicopathologic characteristics

\begin{tabular}{|c|c|c|c|}
\hline Variable & Wait-and Watch $(n=32)$ & Local excision $(n=42)$ & P-value \\
\hline Age (yr) & $64(58-74)$ & $62(54-69)$ & 0.260 \\
\hline Sex & & & 0.815 \\
\hline Male & $20(62.5)$ & $25(59.5)$ & \\
\hline Female & $12(37.5)$ & $17(40.5)$ & \\
\hline Pre-PCRT CEA (ng/mL) & $2.7(1.7-4.0)$ & $1.7(1.2-2.2)$ & 0.001 \\
\hline Concomitant chemotherapeutic regimen & & & 0.004 \\
\hline 5-Fluorouracil/leucovorin & $29(90.7)$ & $25(59.5)$ & \\
\hline Capecitabine & $1(3.1)$ & $16(38.1)$ & \\
\hline FOLFOX or XELOX & $2(6.2)$ & $1(2.4)$ & \\
\hline Pre-PCRT cT category & & & 0.002 \\
\hline cT1-2 & $10(31.3)$ & $29(69)$ & \\
\hline сT3-4 & $22(68.8)$ & $13(31)$ & \\
\hline Pre-PCRT cN category & & & $<0.001$ \\
\hline $\mathrm{CN}(-)$ & $6(18.8)$ & $25(59.5)$ & \\
\hline $\mathrm{cN}(+)$ & 26 (81.3) & $17(40.5)$ & \\
\hline Rectum-sparing at last follow-up time & $28(87.5)$ & $42(100)$ & 0.018 \\
\hline \multicolumn{4}{|l|}{ Salvage treatment indication } \\
\hline Luminal regrowth only & $7(21.9)$ & - & \\
\hline$\geq \mathrm{pT} 2$ & - & $6(14.3)$ & \\
\hline Follow-up duration (mon) & $73(55-90)$ & $65(57-67)$ & 0.725 \\
\hline
\end{tabular}

Values are presented as median (interquartile range) or number (\%).

PCRT, preoperative chemoradiotherapy; CEA, carcinoembryonic antigen; FOLFOX, 5-fluorouracil, leucovorin and oxaliplatin; XELOX, capecitabine and oxaliplatin. 
quiring conservative treatment developed in 1 patient. One patient had pelvic abscess and received stoma formation. Among 9 patients who received salvage resection in the WW group, complications occurred in 3 patients (33.3\%). Among them, 1 patient had internal herniation requiring surgical resection. The others had ileus and voiding difficulty. At last follow-up time, the rectum was preserved in 70 patients $(94.6 \%)$. The rectum-sparing rate was significantly higher in the LE group $(100 \%$ vs. $87.5 \%, \mathrm{P}=$
0.018) at last follow-up.

Overall, in patients with organ preserving approaches, 5-year RFS was $76.9 \%$ and 5 -year OS was $92.6 \%$. The 5-year OS was $93.3 \%$ in the WW group and $92 \%$ in the LE group $(\mathrm{P}=0.668)$. The 5 -year RFS was higher in the LE group (84.6\%) than in the WW group (69.8\%), but it was not statistically different $(\mathrm{P}=0.12)$ (Fig. 2 ). The 5 -year sRFS was significantly lower in patients who received salvage resection $(37.5 \%)$ than in patients who were not in-

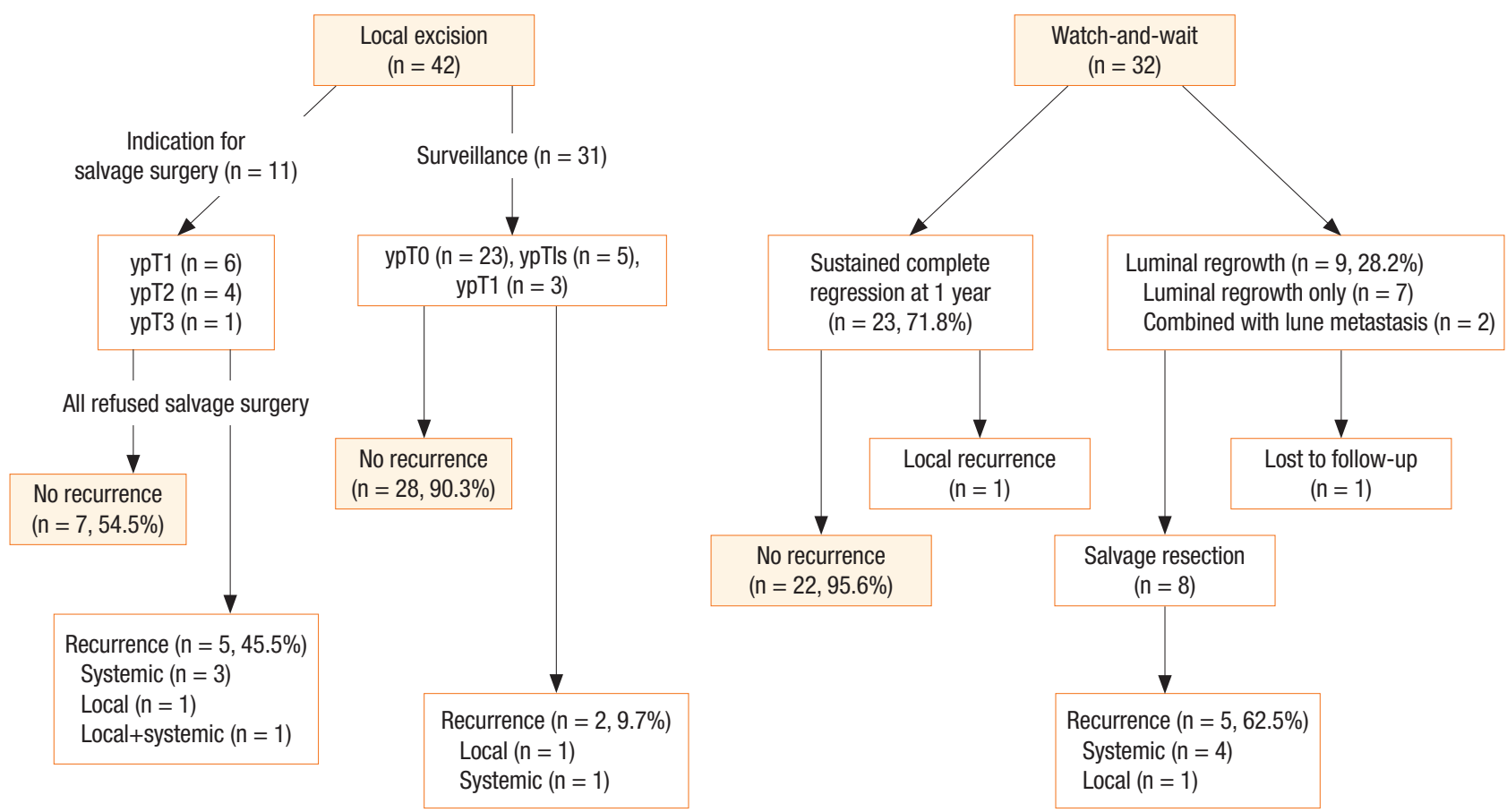

Fig. 1. Organ-preserving approach in patients with rectal cancer treated with preoperative chemoradiotherapy.


Fig. 2. Oncologic outcomes according to type of organ-preserving approach. Recurrence-free survival (A) and overall survival (B). WW, waitand-watch; LE, local excision. 
dicated for salvage resection $(95.5 \%)$ in the WW group $(\mathrm{P}<0.001)$, but 5 -year OS was not different $(87.5 \%$ vs. $95.5 \%, \mathrm{P}=0.691)$. In the LE group, 5 -year OS (62.5\% vs. $97 \%$ ) and sRFS (50\% vs. $91 \%$ ) were both significantly lower in the salvage-indicated group $(\mathrm{P}=$ 0.001 , respectively).

\section{DISCUSSION}

In the present study, 72 patients who received organ-preserving approaches after PCRT for mid and low rectal cancer showed favorable oncologic outcomes in terms of OS and RFS.

Several studies that showed acceptable oncologic outcomes combined with high final rectum preservation rate support organ-preserving approaches. Habr-Gama, a pioneer of the WW approach, reported good oncologic outcomes in patients with cCR to PCRT [14]. Maas et al. [15] included 21 patients with cCR response after PCRT in the WW policy group. They compared oncologic outcomes of the WW group with those of patients who had pathologic CR after surgery. Results showed that RFS and OS were not significantly different between WW patients and patients with pathologic $C R$ who had surgery $(P=0.770$ for $R F S, P=0.228$ for OS), although the mean follow-up duration was not long enough to draw conclusions regarding oncologic outcomes (25 months for WW, 35 months for resection group). A multicenter observational registry study with the International Watch \& Wait Database (IWWD) was recently performed [16]. IWWD is a registry of patients who received PCRT and management by WW. Among 1,009 patients logged in the registry, 880 patients (87\%) achieved cCR status after PCRT. With median follow-up time of 3.3 years, 2 -year cumulative local regrowth rate was $25.2 \%$, and $87.8 \%$ of these patients could be salvaged by surgery.

The present study showed similar results with previous studies in terms of local regrowth, OS, and RFS. Because regrowth is considered recurrence, RFS was $76.9 \%$ while OS was up to $93.3 \%$ in the WW group. Salvage rate was $88.9 \%$, and no patients refused salvage resection.

A major limitation of $\mathrm{WW}$ is that it is a limited diagnostic method to determine clinical CR. Although mrTRG using MRI has been accepted as a method to better correspond to pathologic evaluation, accuracy is not satisfactory [17-19]. For nodal staging, it was more difficult to diagnose even in patients who did not receive PCRT [20]. Therefore, LE is attractive because it allows pathologic TRG. Pathologic confirmation of tumor regression with LE allows identification of patients indicated for salvage resection and early salvage. However, according to a previous study of LE after PCRT, the salvage resection rate was usually around $50 \%[8,9,21]$. Considering the salvage rate in $\mathrm{WW}$ approaches $50 \%-100 \%[15,22,23], \mathrm{LE}$ in the present study did not get the benefit of pathologic examination. Indeed, surgical morbidity was reported to be $3.8 \%-44.4 \%$ after LE $[8,9,21]$. Suture dehiscence and rectal pain were the major surgical morbidities. However, we also realize that postoperative complications after salvage resec- tion in WW exceeded those of LE. We need to find a way to give salvage resection in an effective way for indicated patients after LE and carefully evaluate oncologic and clinical outcomes after salvage resection to achieve improved oncologic outcomes and satisfactory quality of life.

Because of limitations in the diagnosis method after PCRT and concerns for residual cancer in the bowel wall or mesorectum, intensive surveillance usually followed WW and LE. The surveillance schedule varies by institution. In the first 2 years, surveillance endoscopy and MRI were performed every 2 or 3 months. Local regrowth was reported as $5 \%-60 \%$ in previous studies [ 8 , $10,16,21,24]$. The IWWD reported that $24 \%$ showed local regrowth and $88 \%$ occurred within 2 years. Most regrowth was confined within the bowel wall [16].

This study showed similar outcomes; $21.9 \%$ showed no metastasis regrowth, all of which occurred within 2 years. Distant metastasis sites were all lung, and metastasis occurred 7 to 8 months after completion of PCRT. One patient had mesorectal lymph node metastasis diagnosed immediately after salvage LE. Mesorectal lymph node metastasis was not frequent in previous studies on WW. Surveillance should focus on luminal recurrence during the first 2 years. Appropriate methods and intervals to detect systemic metastasis or mesorectal nodes continue to be discussed. The 3-year RFS after salvage surgery in WW was $57.1 \%$, but the 5 -year OS in patients who received salvage surgery was $77.9 \%$. Postsalvage recurrence developed within 1 year after salvage in 4 of 5 patients who experienced salvage resection. In other studies reporting postsalvage recurrence, most recurrences occurred within 2 years after salvage $[22,23,25]$. Proper postsalvage surveillance methods and intervals must be further evaluated. The implications of intensive surveillance on oncologic outcomes also require further evaluation.

At the last follow-up, rectum preservation was significantly higher in the LE group than in the WW group. However, this was caused by avoidance of salvage surgery in the LE group. This study showed good overall survival after organ-preserving approach for patients with cCR after PCRT for rectal cancer. Further investigations are needed to improve salvage treatment rate after LE and determine the clinical benefit of early salvage. Limitations of this study include its retrospective nature and that included patients are heterogeneous and from a single center. Regardless of its limitations, this study provides practical information regarding treatment of rectal cancer with PCRT. A prospective study would be helpful to investigate organ-preserving approaches in patients with rectal cancer treated with PCRT.

\section{CONFLICT OF INTEREST}

No potential conflict of interest relevant to this article was reported. 


\section{ACKNOWLEDGMENTS}

This study was supported by the National Research Foundation of Korea (NRF) (2016R1A2B4014039) and was also supported by grants (2016-0793, 2017-0791) from the Asan Institute for Life Sciences, Asan Medical Center, Seoul, and Republic of Korea.

\section{REFERENCES}

1. Paun BC, Cassie S, MacLean AR, Dixon E, Buie WD. Postoperative complications following surgery for rectal cancer. Ann Surg 2010;251:807-18.

2. Juul T, Ahlberg M, Biondo S, Espin E, Jimenez LM, Matzel KE, et al. Low anterior resection syndrome and quality of life: an international multicenter study. Dis Colon Rectum 2014;57:585-91.

3. Fazio VW, Zutshi M, Remzi FH, Parc Y, Ruppert R, Fürst A, et al. A randomized multicenter trial to compare long-term functional outcome, quality of life, and complications of surgical procedures for low rectal cancers. Ann Surg 2007;246:481-8.

4. Lange MM, Maas CP, Marijnen CA, Wiggers T, Rutten HJ, Kranenbarg EK, et al. Urinary dysfunction after rectal cancer treatment is mainly caused by surgery. Br J Surg 2008;95:1020-8.

5. Sauer R, Fietkau R, Wittekind C, Rödel C, Martus P, Hohenberger $\mathrm{W}$, et al. Adjuvant vs. neoadjuvant radiochemotherapy for locally advanced rectal cancer: the German trial CAO/ARO/AIO-94. Colorectal Dis 2003;5:406-15.

6. Park IJ, You YN, Agarwal A, Skibber JM, Rodriguez-Bigas MA, Eng C, et al. Neoadjuvant treatment response as an early response indicator for patients with rectal cancer. J Clin Oncol 2012;30: 1770-6.

7. Fokas E, Liersch T, Fietkau R, Hohenberger W, Beissbarth T, Hess $\mathrm{C}$, et al. Tumor regression grading after preoperative chemoradiotherapy for locally advanced rectal carcinoma revisited: updated results of the CAO/ARO/AIO-94 trial. J Clin Oncol 2014; 32:1554-62.

8. Bujko K, Richter P, Smith FM, Polkowski W, Szczepkowski M, Rutkowski A, et al. Preoperative radiotherapy and local excision of rectal cancer with immediate radical re-operation for poor responders: a prospective multicentre study. Radiother Oncol 2013; 106:198-205.

9. Guerrieri M, Gesuita R, Ghiselli R, Lezoche G, Budassi A, Baldarelli $\mathrm{M}$. Treatment of rectal cancer by transanal endoscopic microsurgery: experience with 425 patients. World J Gastroenterol 2014;20:9556-63.

10. Garcia-Aguilar J, Renfro LA, Chow OS, Shi Q, Carrero XW, Lynn $\mathrm{PB}$, et al. Organ preservation for clinical T2N0 distal rectal cancer using neoadjuvant chemoradiotherapy and local excision (ACOSOG Z6041): results of an open-label, single-arm, multi-institutional, phase 2 trial. Lancet Oncol 2015;16:1537-46.

11. Kalady MF, de Campos-Lobato LF, Stocchi L, Geisler DP, Dietz D, Lavery IC, et al. Predictive factors of pathologic complete response after neoadjuvant chemoradiation for rectal cancer. Ann
Surg 2009;250:582-9.

12. Tulchinsky H, Shmueli E, Figer A, Klausner JM, Rabau M. An interval $>7$ weeks between neoadjuvant therapy and surgery improves pathologic complete response and disease-free survival in patients with locally advanced rectal cancer. Ann Surg Oncol 2008;15:2661-7.

13. Chang HJ, Park CK, Kim WH, Kim YB, Kim YW, Kim HG, et al. A standardized pathology report for colorectal cancer. The Korean J Pathol 2006;40:193-203.

14. Habr-Gama A, Perez RO, Nadalin W, Sabbaga J, Ribeiro U Jr, Silva e Sousa AH Jr, et al. Operative versus nonoperative treatment for stage 0 distal rectal cancer following chemoradiation therapy: long-term results. Ann Surg 2004;240:711-7.

15. Maas M, Beets-Tan RG, Lambregts DM, Lammering G, Nelemans PJ, Engelen SM, et al. Wait-and-see policy for clinical complete responders after chemoradiation for rectal cancer. J Clin Oncol 2011;29:4633-40.

16. van der Valk MJM, Hilling DE, Bastiaannet E, Meershoek-Klein Kranenbarg E, Beets GL, Figueiredo NL, et al. Long-term outcomes of clinical complete responders after neoadjuvant treatment for rectal cancer in the International Watch \& Wait Database (IWWD): an international multicentre registry study. Lancet 2018;391:2537-45.

17. Patel UB, Brown G, Rutten H, West N, Sebag-Montefiore D, Glynne-Jones R, et al. Comparison of magnetic resonance imaging and histopathological response to chemoradiotherapy in locally advanced rectal cancer. Ann Surg Oncol 2012;19:2842-52.

18. Sclafani F, Brown G, Cunningham D, Wotherspoon A, Mendes LS, Balyasnikova S, et al. Comparison between MRI and pathology in the assessment of tumour regression grade in rectal cancer. Br J Cancer 2017;117:1478-85.

19. Lambregts DM, Maas M, Bakers FC, Cappendijk VC, Lammering G, Beets GL, et al. Long-term follow-up features on rectal MRI during a wait-and-see approach after a clinical complete response in patients with rectal cancer treated with chemoradiotherapy. Dis Colon Rectum 2011;54:1521-8.

20. Heijnen LA, Maas M, Beets-Tan RG, Berkhof M, Lambregts DM, Nelemans PJ, et al. Nodal staging in rectal cancer: why is restaging after chemoradiation more accurate than primary nodal staging? Int J Colorectal Dis 2016;31:1157-62.

21. Perez RO, Habr-Gama A, São Julião GP, Proscurshim I, Fernandez LM, de Azevedo RU, et al. Transanal endoscopic microsurgery (TEM) following neoadjuvant chemoradiation for rectal cancer: outcomes of salvage resection for local recurrence. Ann Surg Oncol 2016;23:1143-8.

22. Habr-Gama A, Gama-Rodrigues J, São Julião GP, Proscurshim I, Sabbagh C, Lynn PB, et al. Local recurrence after complete clinical response and watch and wait in rectal cancer after neoadjuvant chemoradiation: impact of salvage therapy on local disease control. Int J Radiat Oncol Biol Phys 2014;88:822-8.

23. Renehan AG, Malcomson L, Emsley R, Gollins S, Maw A, Myint AS, et al. Watch-and-wait approach versus surgical resection after 
chemoradiotherapy for patients with rectal cancer (the OnCoRe project): a propensity-score matched cohort analysis. Lancet Oncol 2016;17:174-83.

24. Appelt AL, Pløen J, Harling H, Jensen FS, Jensen LH, Jørgensen JC, et al. High-dose chemoradiotherapy and watchful waiting for distal rectal cancer: a prospective observational study. Lancet Oncol 2015;16:919-27.

25. Glynne-Jones R, Hughes R. Critical appraisal of the 'wait and see' approach in rectal cancer for clinical complete responders after chemoradiation. Br J Surg 2012;99:897-909. 